\title{
Effect of the Size and Position of a Damping Ditch on the Reduction of the Blasting Vibration
}

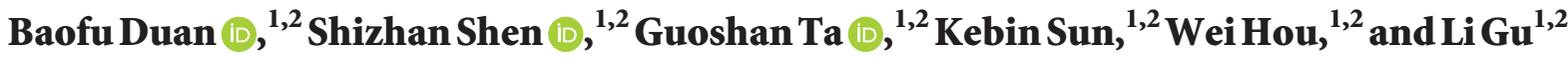 \\ ${ }^{1}$ Key Laboratory of Civil Engineering Disaster Prevention and Mitigation, Shandong University of Science and Technology, \\ Qingdao, Shandong 266590, China \\ ${ }^{2}$ College of Civil Engineering and Architecture, Shandong University of Science and Technology, Qingdao, \\ Shandong 266590, China \\ Correspondence should be addressed to Shizhan Shen; 18300251210@163.com
}

Received 26 March 2020; Revised 17 June 2020; Accepted 20 July 2020; Published 4 August 2020

Academic Editor: Agathoklis Giaralis

Copyright (c) 2020 Baofu Duan et al. This is an open access article distributed under the Creative Commons Attribution License, which permits unrestricted use, distribution, and reproduction in any medium, provided the original work is properly cited.

\begin{abstract}
The size and position of the damping ditch have a direct impact on the blasting vibration. In order to explore the effect of damping ditches of different sizes and positions, we investigated field blasting in the A3 area of the second phase of the Lufeng Nuclear Power Plant project. The simulation software ANSYS/LS-DYNA was used to simulate the vibration propagation of damping ditches with different depths, widths, and positions. Secondly, the vibration data of the corresponding measuring points were collected and the amplitude reduction was analyzed in different situations. An analysis of the numerical simulation results showed that an increase in the damping ditch width increased the vibration amplitude at the top of the building. The depth and position of the damping ditch were the main factors affecting the damping performance. A regression analysis was conducted using the Sadove equation for vibration velocity. It was found that the regression coefficient of the Sadove equation did not meet the required standards when a damping ditch was present. The vibration attenuation equations were fitted for the top and the base of the building. The results of this study provide reference data for the excavation and arrangement of damping ditches in practical applications.
\end{abstract}

\section{Introduction}

Blasting is widely used in various engineering fields due to its high efficiency and cost-effectiveness. However, blasting has many negative effects and the vibration impact is the most significant one. When the blasting vibration waves propagate through the rock to buildings, the buildings vibrate. When the vibration intensity exceeds the safety threshold, the building may be damaged. In order to reduce the impact of the blasting vibration, a damping ditch is usually excavated between the source and the buildings; the size and position of the damping ditch have a direct impact on the damping effect. Therefore, research on the size and position of the damping ditch has important practical and theoretical value.

Domestic and foreign scholars have conducted research on damping ditches for vibration reduction in various engineering fields. In addition to applications in blasting engineering, damping ditches are also widely used to minimize the vibrations from railways. Several scholars have investigated the vibration isolation effects of different types of damping ditches. Wang et al. [1] studied the effects of damping ditches with different widths and depths on the blasting vibration attenuation using finite element software. It was found that the width of the ditch had little effect on the damping effect when all other conditions were constant; the deeper the damping ditch, the better the damping effect. Yu et al. [2] used ANSYS/LS-DYNA to simulate step blasting with and without a damping ditch and compared the peak particle velocity (PPV) of the interior and surface of the rock mass. It was found that the attenuation of the body wave was related to the depth and width of the damping ditch, whereas the attenuation of the surface wave was only related to the depth of the damping ditch. Zoccali et al. [3] studied the 
effect of the length of the damping ditch and different fill materials on vibration damping using the finite element method. The results showed that a longer damping ditch provided a better damping effect. Persson et al. [4] explored the damping effects of various damping ditches using the finite element model and found that the depth of the damping ditch and the solidity of the backfill material were the most influential factors. Saikia et al. $[5,6]$ used the finite element software PLAXIS for a numerical study of the vibration effect of a rectangular damping ditch in a planestrain environment. The horizontal and vertical vibration damping effects of different sizes of damping ditches were investigated based on the assumption of linear elasticity. It was found that the damping ditch width had almost no effect on vibration damping. Esmaeili et al. [7] numerically simulated the damping effects of damping ditches with different shapes. The results showed that the vibration damping effect was better for a V-shaped damping ditch than for an ordinary rectangular damping ditch at train speeds of $80-120 \mathrm{~km} / \mathrm{h}$. Zakeri et al. [8] used Abaqus software to simulate the damping effect of open and filled step-type damping ditches. It was determined that the step-type damping ditch had a better damping effect than the ordinary rectangular damping ditch. Jesmani et al. [9] used the ANSYS/LS-DYNA three-dimensional finite element software to determine the effect of the angle and radius of the arc of the damping ditch on the vibration damping. The results showed that the larger the radius of the arc of the damping ditch, the wider the protection range; in addition, an increase in the angle increased the rate of decrease in the vibration amplitude. Thompson et al. [10] used the finite element method to investigate the vibration reduction effect of different sizes of damping ditches under different ground stratification conditions. It was determined that the vibration damping performance was optimum for the rectangular vibration damping ditch; the damping ditch depth was an important factor, whereas the width had little effect on the vibration damping performance. Hamdan et al. [11] used an unstructured-grid numerical model to study the vibration attenuation effects of different shapes of damping ditches. It was found that the effect of the rectangular damping ditch was excellent and convenient for on-site applications; the damping effect was not affected by the inclination angle of the groove. Van Hoorickx et al. [12] and Younesian and Sadri [13] used the finite element method to study the damping effect of paired damping ditches. The results showed that the damping performance was significantly better for the paired damping ditch system than the single damping ditch; the distance between the paired ditches had a significant effect on the damping performance. In terms of filled damping grooves. Ju and Li [14] and Barbosa et al. [15] analyzed the damping effect of damping ditches with different fill materials using finite element analysis. It was found that the water-filled groove had low damping efficiency in the $Y$-direction of the wave. Ding et al. [16] conducted an on-site blasting test and vibration monitoring with and without a damping ditch. It was determined that the damping ditch had an attenuation effect on the blasting vibration energy; however, energy amplification was observed at a certain distance from the ditch. Zheng et al. [17] used the vibration of a drop hammer in a simulated vibration damping test. It was determined that the vibration of the damping ditch had a significant effect on the horizontal radial vibration in terms of PPV, whereas the effect on the vertical vibration velocity was minor. Ulgen and Toygar [18] investigated the damping effect of open, water-filled, and foam-filled filled damping ditches using a series of field tests. It was determined that the geofoam-filled trench had the best vibration damping performance. Ekanayake et al. [19] studied the damping performance of an open and filled damping ditch and found that an increase in the depth of the filled groove significantly improved the damping performance. Alzawi and Naggar [20] investigated the vibration reduction performance of open and filled damping ditches using field tests and numerical simulations. The results showed that the damping performance was lower for the open damping ditch than the filled ditch when the distance between the damping ditch and the vibration source was short. Jayawardana et al. [21] studied the vibration attenuation effect of a damping ditch during piling installation using field tests and numerical simulations. It was determined that the open damping ditch and water-filled damping ditch exhibited better performance than other types of damping ditches. For the damping ditches, the outstanding contributions made by scholars are shown in Table 1.

The abovementioned researchers analyzed the influence of damping ditches on the vibration reduction from different aspects such as the size, shape, position, and fill material of the damping ditch and in different fields. Excellent results have been obtained, especially in the field of railway vibration isolation. However, due to field test limitations in the field of blasting, most researchers have focused on qualitative analyses and numerical simulations of the vibration reduction by investigating one-dimensional changes or changes in the position of the damping ditch. Few researchers have quantitatively analyzed the effect of the simultaneous change in the size and position of the damping ditch on the damping performance. Therefore, in this study, we explore the effects of damping ditches with different depths, widths, and positions on the vibrations at the base and top of a lighthouse using numerical simulations.

\section{Engineering Background}

Lufeng Nuclear Power Plant Phase II A3 regional field blasting project is located at the southern end of the coastal peninsula south of Jieshi Town, Lufeng City, Guangdong Province. According to geological exploration data, the rock in the area of the nuclear power plant is slightly weathered granite. The blasting excavation of the site leveling project in Area A3 is close to the newly built lighthouse, which is about 100 meters. The lighthouse is a hollow cylinder with a diameter of $6 \mathrm{~m}$ and a height of $36 \mathrm{~m}$. In order to reduce the blasting vibration and protect the safety of the newly built lighthouse, between the excavation area and the newly built lighthouse, a vibration damping ditch is excavated from the location of the explosion source $20 \mathrm{~m}$ and the lighthouse 
TABLE 1: Domestic and foreign scholars have conducted research on damping ditches for vibration reduction.

The characteristic of the damping ditches

Different types of damping ditches

Different shapes

The damping effect of paired damping ditches

Research results of scholars

Persson et al. [4] and Ekanayake et al. [19] found that an increase in the depth of the filled groove significantly improved the damping performance; Zoccali et al. [3] considered that a longer damping ditch provided a better damping effect; Saikia and Das [5], Wang et al. [1], Yu et al. [2], Saikia et al. [5, 6], and Thompson et al. [10] found that the damping ditch width had almost no effect on vibration damping.

Thompson et al. [10] and Hamdan et al. [11] found that the effect of the rectangular damping ditch was excellent and convenient for on-site applications; Esmaeili et al. [7] showed that the vibration damping effect was better for a $\mathrm{V}$-shaped damping ditch than for an ordinary rectangular damping ditch; Zakeri et al. [8] was determined that the step-type damping ditch had a better damping effect than the ordinary rectangular damping ditch; Jesmani et al. [9] showed that the larger the radius of the arc of the damping ditch, the wider the protection range; in addition, an increase in the angle increased the rate of decrease in the vibration amplitude.

Van Hoorickx et al. [12] and Younesian and Sadri [13] found that the damping performance was significantly better for the paired damping ditch system than the single damping ditch; the distance between the paired ditches had a significant effect on the damping performance.

Jayawardana et al. [21] determined that the open damping ditch and water-filled damping ditch exhibited better performance than other types of damping ditches; Ulgen and Toygar [18] determined that the geofoam-filled trench had the best vibration damping performance; Ju et al. [14] and Barbosa et al. [15] found that the water-filled groove had low damping efficiency in the $Y$ direction of the wave; Alzawi and Naggar [20] found that the damping performance was lower for the open damping ditch than the filled ditch when the distance between the damping ditch and the vibration source was short.

$23 \mathrm{~m}$ away. The damping ditch width is $1.5 \mathrm{~m}$, the depth is $5 \mathrm{~m}$, and the length is $13 \mathrm{~m}$. Vibration monitoring of lighthouse during blasting excavation. Figure 1 is a schematic diagram of the location of the explosion source, the damping ditch and the lighthouse, and the measuring point.

In this study, we focus on a blasting project and consider the geological conditions, the size and location of the building, and the damping ditch. We use numerical simulations to determine the influence of the size and position of the damping ditch on the damping performance at the ground surface and the top of the lighthouse.

\section{Numerical Calculation of the Damping Ditch Model}

3.1. Model Size. The nonlinear dynamic finite element software ANSYS/LS-DYNA was used to analyze the vibration attenuation at the top and base of the lighthouse for different damping ditch sizes and positions. The numerical model dimensions were based on a $1: 1$ ratio and the basic unit of the selection parameters was $\mathrm{cm}-\mathrm{g}-\mu \mathrm{s}$. In order to avoid the effect of the damping ditch length on the vibration damping effect performance, the same length was used for the damping in the entire model.

In order to separately explore the effects of the damping ditch depth $(d)$, the damping ditch width $(w)$, and the damping ditch position which was represented by the distance (the distance from the back wall of the damping ditch to the lighthouse), the numerical simulation was divided into four groups. Each group has a No. 0 model without a damping ditch to serve as the control. In order to avoid errors, the dimensions of all model foundations were
$6000 \mathrm{~cm} * 3000 \mathrm{~cm} * 3000 \mathrm{~cm}$. The sizes and positions of the damping ditches in each group are shown in Table 2.

Various numerical calculation models are established according to the damping ditch size of Table 2 . The model diagrams are shown in Figure 2.

3.2. Unit Selection and Meshing. The most suitable unit types for blast analysis in LS-DYNA are the two-dimensional solid 162 and three-dimensional solid 164 units (finite elements type). We used the 8-node three-dimensional solid 164 units. Three parts are defined in the model; namely, the explosive is part 1 , the rock mass is part 2, and the lighthouse is part 3. The Lagrangian algorithm is used to describe part 2 and part 3, and Arbitrary Lagrange-Euler is used to describe part 1.

The grid is divided by sweeping. For the location of the foundation and the shape of the lighthouse, a simple segmentation was used for the meshing. In general, the smaller the size of the grid unit, the higher the calculation accuracy, but the larger the memory and time requirements. In order to avoid waveform distortion and ensure the calculation accuracy, the cell size must be less than one-tenth to oneeighth of the wavelength [22]. The model mesh was gradually refined from the ground model boundary to the boundary region unit of the explosive source. The direction of gravity was the negative direction of the $Z$-axis, the positive direction of the $Y$-axis was the longitudinal direction of the vertical damping ditch, and the $X$-axis direction was parallel to the longitudinal direction of the damping ditch. The explosion source was located at the center of one end of the model, the distance to the boundary was $1500 \mathrm{~cm}$, the 


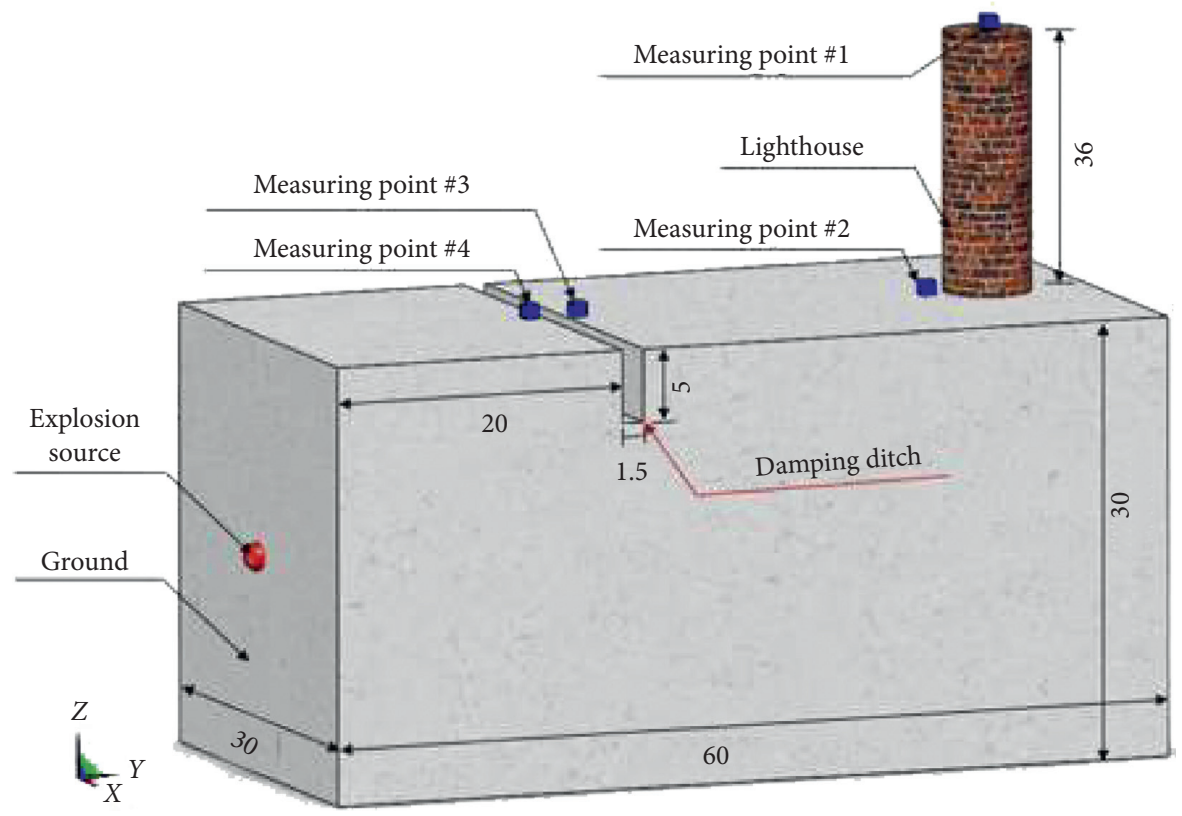

FIgURE 1: Schematic diagram of the vibration source, damping ditch, and lighthouse location (unit: $\mathrm{m}$ ).

TABle 2: Damping ditch size of each model.

\begin{tabular}{|c|c|c|c|c|c|c|c|c|c|c|c|c|c|c|c|c|}
\hline Num & $1-1$ & $1-2$ & $1-3$ & $1-4$ & $2-1$ & $2-2$ & $2-3$ & -4 & -1 & $3-2$ & -3 & $3-4$ & 4-1 & $4-2$ & 4-3 & $4-4$ \\
\hline & & & 1425 & 1050 & 900 & 800 & & 900 & & & & ono & 750 & 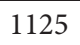 & 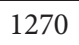 & 725 \\
\hline & & & & & & & & & & & & & & & 2 & 345 \\
\hline Distance $(\mathrm{cm})$ & 350 & 350 & 2350 & 2350 & 2350 & 2350 & 2350 & 2350 & 3555 & 3105 & 2350 & 1605 & 3405 & 3330 & 2670 & 2280 \\
\hline
\end{tabular}
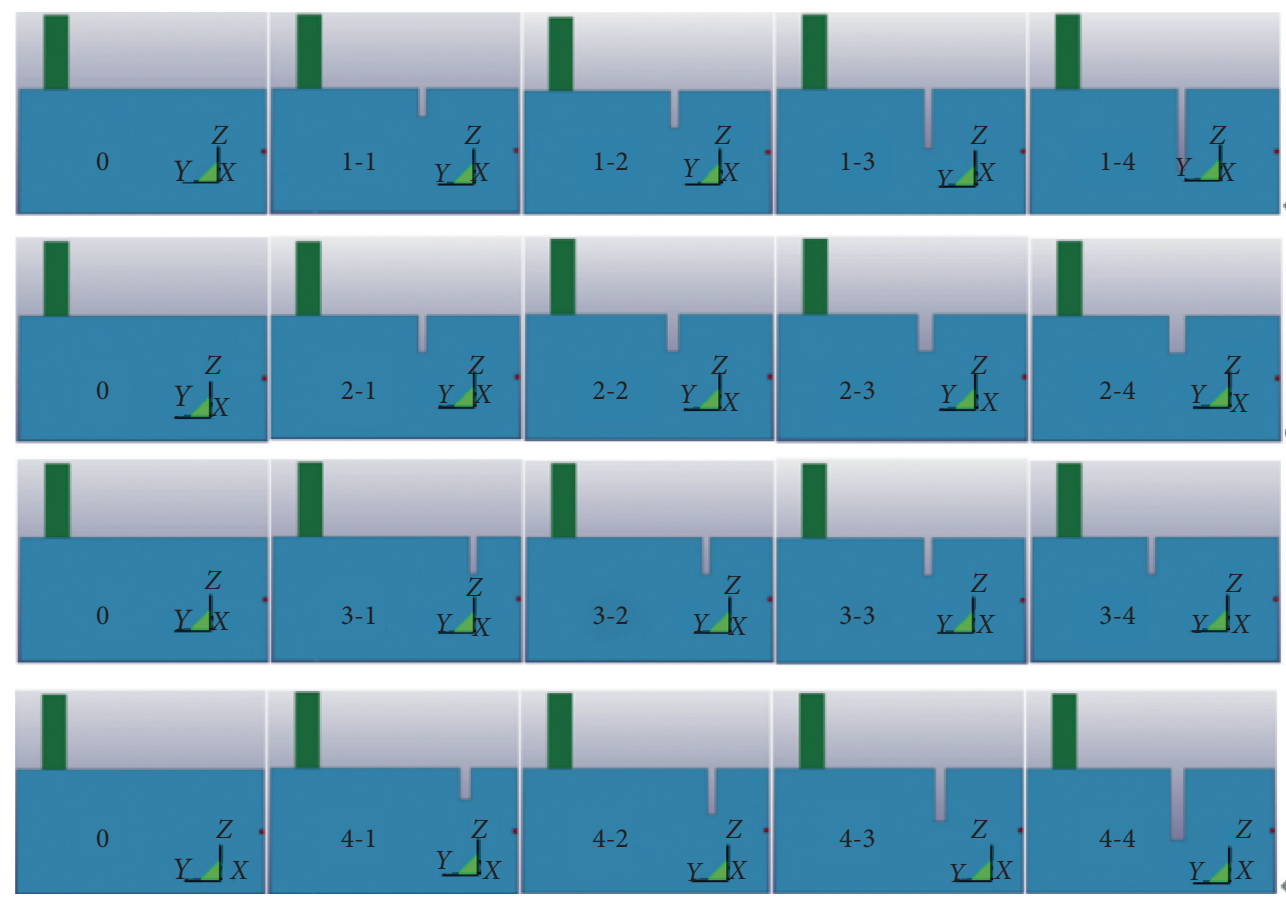

FIGURE 2: Groups of test models used in the numerical calculation. 


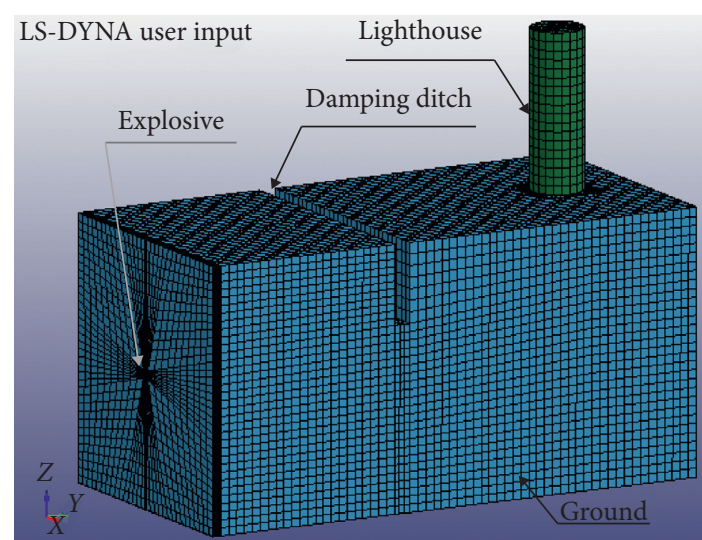

FIgure 3: Mesh of the model.

distance to the other end of the model was $900 \mathrm{~cm}$, and the distance to the other two boundaries was equal. The position and mesh division are shown in Figure 3.

\subsection{Material Used in the Model and Equation of State.} Many factors influence the propagation of blasting vibration waves. In order to avoid the influence of various geological conditions such as jointed fractured rock layers on the propagation of the seismic waves, the dynamic response of the damping ditches to the propagation of blasting vibration waves is highlighted. We selected slightly weathered granite as the rock mass and the granite rock mass parameters as the physical and mechanical parameters of the original rock. The constitutive model has an important influence on the accuracy of the calculation results. Rock and concrete are anisotropic materials. During blasting, the rock is subjected to ultra-high pressure in an instant and undergoes large deformation and high strain. In order to accurately simulate the changes in the rock under detonation and ensure the accuracy of the simulation results, we used the $*$ MAT_PLASTIC_KINEMATIC (plastic follow-up hardening model) material model with the von Mises yield criterion; the material parameters [23] are shown in Table 3.

$l$ and $l_{0}$ are the lengths of the non-axial tensile specimen before and after deformation and $E_{t}$ is the slope of the bilinear stress-strain curve.

The model considers the effect of strain rate, and its constitutive relationship [24] is

$$
\sigma_{y}=\left[1+\left(\frac{\dot{\varepsilon}}{C}\right)^{1 / P}\right]\left(\sigma_{0}+\beta E_{P} \varepsilon_{\text {eff }}^{P}\right) .
$$

Among them, $\sigma_{y}$ is the increased yield stress; $\dot{\varepsilon}$ is the strain rate; $C$ is the strain coefficient; $\sigma_{0}$ is the critical stress; $\beta$ is the strengthening coefficient; and $E_{P}$ and $\varepsilon_{\text {eff }}$ are the plastic modulus and effective plastic strain, respectively.

Follow-up reinforcement, isotropic reinforcement, or joint isotropic follow-up reinforcement is defined by $\beta$, $0 \leq \beta \leq 1$. When $\beta=0$ only follow-up strengthening is considered; at $\beta=1$, only isotropic strengthening is considered.

We used an "integral" algorithm for the reinforced concrete lighthouse to ensure that the strength of the steel is equal to that of concrete. We used the $*$ MAT_JOHNSON_HOLMQUIST_CONCRETE (referred to as JHC model) material model to simulate the lighthouse [25-27]; the material parameters are shown in Table 4.

The constitutive calculation model is as follows:

$$
\sigma^{*}=\left[A(1-D)+\mathrm{BP}^{* N}\right][1-C \ln (\dot{\varepsilon})],
$$

where $\sigma^{*}=\sigma / f_{c}^{\prime}$ is the normalized equivalent yield stress, $f_{c}^{\prime}=0.048 \mathrm{GPa}$ is the quasi-static uniaxial compression yield strength, $D$ is the amount of damage, $P^{*}=P / f_{c}^{\prime}$ is the normalized hydrostatic pressure, $\dot{\varepsilon}^{*}=\dot{\varepsilon} / \dot{\varepsilon}_{0}$ is a dimensionless strain rate, $\dot{\varepsilon}_{0}$ is the reference strain rate, $A$ is the normalized viscosity strength, $B$ is the normalized pressure enhancement factor, $N$ is the pressure hardening index, and $C$ is the strain rate factor.

In many engineering projects, the No. 2 rock emulsion explosive is used; we used the $*$ MAT_HIGH_EXPLOSIVE_ BURN material model in the simulation to simulate the Jones-Wilkins-Lee (JWL) [28-30] equation of state of the pressure and specific volume relationship during the explosion, as shown in the following:

$$
P=A\left(1-\frac{\omega}{R_{1} V}\right) e^{-R_{1} V}+B\left(1-\frac{\omega}{R_{2} V}\right) e^{-R_{2} V}+\frac{\omega E_{0}}{V},
$$

where $A, B, R_{1}, R_{2}$, and $\omega$ are material constants; $P$ is the pressure; $V$ is the relative volume; and $E_{0}$ is the initial ratio of the internal energy. The parameters of the explosive and the JWL equation of state parameters are shown in Table 5.

3.4. Boundary Settings. In order to prevent the model boundary stress wave reflection from affecting the experimental results, the model is set to a non-reflective boundary except for the surrounding and bottom of the damping ditch. Really reflecting the transmission of vibration waves in the foundation, it is possible to simulate an infinite foundation space with a finite model area. At the same time, the explosion source is $15 \mathrm{~m}$ away from the peripheral boundary, which guarantees a sufficient calculation range to some extent. The lateral boundary of the model foundation is applied with the normal direction displacement constraint of the surface, and the bottom surface is fully constrained. The ground and above are free boundaries.

3.5. Simulation Results. In this simulation, the depth of the rock is $30 \mathrm{~m}$; therefore, the influence of the rock's own weight is non-negligible during blasting. Prior to the power calculation, gravity is applied to the entire model using the $K$ file.

It is observed in the stratum stress cloud map of the vibration wave propagation (see Figure 5) that the initial gravity of the self-weight changes from blue to green from the top to the bottom; the deeper the stratum, the greater the stress. The uniformity provides good initial stress conditions for the subsequent blasting calculations. From $0.9 \mathrm{~ms}$ to $49 \mathrm{~ms}$, the blasting vibration wave propagates in the formation and finally stabilizes. The vibration wave 
TABLE 3: Material parameters of the rock model.

\begin{tabular}{lcc}
\hline$\rho /\left(\mathrm{g} \cdot \mathrm{cm}^{3}\right)$ & Density & 0.1 \\
$\mathrm{G} / \mathrm{GPa}$ & Shear modulus & 14.8 \\
$\mathrm{~A}$ & Normalized cohesive & 0.79 \\
$\mathrm{~B}$ & Normalized pressure hardening & 1.6 \\
$\mathrm{C}$ & Strain rate coefficient & 0.007 \\
$\mathrm{~N}$ & Pressure hardening exponent & 0.61 \\
$\mathrm{FC} / \mathrm{MPa}$ & Quasi-static uniaxial compressive strength & 48 \\
$\mathrm{~T} / \mathrm{MPa}$ & Maximum tensile hydrostatic pressure & 4 \\
$\mathrm{EPSO}$ & Reference strain rate & 0.001 \\
$\mathrm{EFMIN}$ & Amount of plastic strain before fracture \\
$\mathrm{SFMAX} / \mathrm{GPa}$ & Normalized maximum strength & 0.01 \\
$\mathrm{PC} / \mathrm{MPa}$ & Crushing pressure & 7 \\
$\mathrm{UC}$ & Crushing volumetric strain \\
$\mathrm{PL} / \mathrm{MPa}$ & Locking pressure \\
$\mathrm{UL}$ & Locking volumetric strain \\
$D_{1}$ & Damage constant \\
$D_{2}$ & Damage constant \\
$K_{1}, K_{2}, K_{3} / \mathrm{GPa}$ & Pressure constant & 16 \\
\hline
\end{tabular}

We used the $*$ MAT_PLASTIC_KINEMATIC (plastic follow-up hardening model) material model mechanical properties shown in Figure 4.

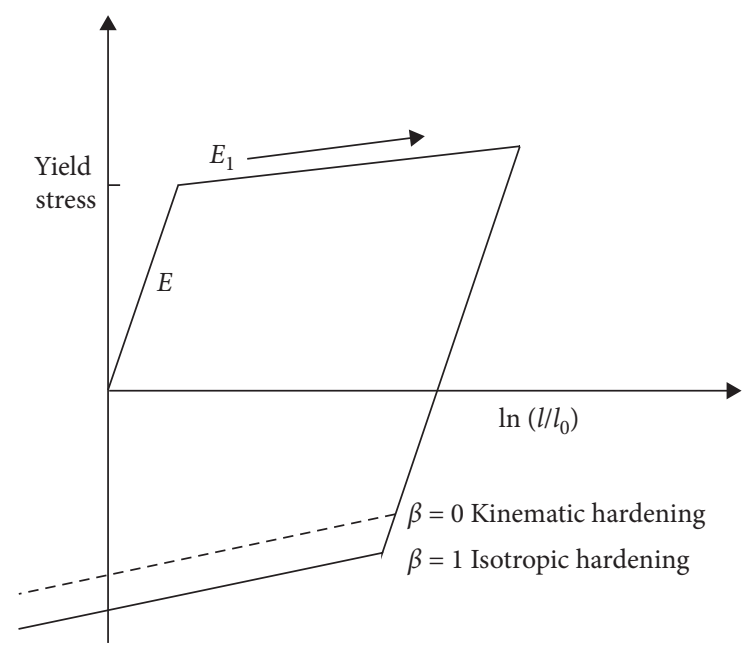

FIGURE 4: Elastoplastic behavior of follow-up strengthening and isotropic strengthening.

TABLE 4: Material parameters of the reinforced concrete lighthouse model.

\begin{tabular}{lcc}
\hline$\rho /\left(\mathrm{g} \cdot \mathrm{cm}^{3}\right)$ & Density & 2.63 \\
$\mathrm{G} / \mathrm{GPa}$ & Shear modulus & 53.1 \\
$\mathrm{PR}$ & Poisson's ratio & 0.25 \\
SIGY & Yield stress & 170 \\
ETAN & Tangent modulus & 0.212 \\
BETA & Initiation condition control & 1 \\
FS & Failure strain & 0.06 \\
\hline
\end{tabular}

TABLE 5: Parameters of the explosive and the JWL equation of state.

\begin{tabular}{lccccccc}
\hline$\rho /\left(\mathrm{g} \cdot \mathrm{cm}^{3}\right)$ & $D /\left(m s^{-1}\right)$ & $A / \mathrm{GPa}$ & $B / \mathrm{GPa}$ & $R_{1}$ & $R_{2}$ & $\omega$ & $E_{0} / \mathrm{GPa}$ \\
\hline 1.2 & 3600 & 214.4 & 18.2 & 4.2 & 0.9 & 0.15 & 4.19
\end{tabular}

propagation is in good agreement with the theory, indicating that the calculation results are appropriate.

After the modeling, the particle velocity extraction function of the ls-prepost post-processing was used to obtain the vibration data in the three directions of the $\# 1, \# 2, \# 3$, and \#4 points measured in the project. In order to facilitate comparison of the amplitude and peak value of the timehistory curve of the vibration speed of the No. 0 model $1 \#$ and $2 \#$, draw the $X, Y, Z$ vibration speed time history curves of the measuring points, the No. 0 model $1 \#$ and $2 \#$ in the three-dimensional graph, as shown in Figures 6 and 7.

It is observed in Figure 6 that, in the No. 0 model, there are significant vibration fluctuations in the three directions at the top of the tower (\#1 measuring point). The reason is that more movement occurs at the top of the lighthouse as a result of blasting, thereby affecting the vibrations.

It can be observed in Figure 7 that, for the No. 0 model, the three-direction vibration waveform in front of the lighthouse (\#2 measuring point) is obviously attenuated relative to the $1 \#$ measuring point, and the PPV of threedirection is $V_{x}=2.896 \mathrm{~cm} / \mathrm{s}, \quad V_{y}=3.072 \mathrm{~cm} / \mathrm{s}$, and $V_{z}=1.38 \mathrm{~cm} / \mathrm{s}$. Like the \# 1 measuring point, the $\mathrm{PPV}$ in the $Y$-direction is the largest.

It can be observed from the peak velocity law of the No. 0 model \#1 and \#2 measuring points that, in the remote area of blasting vibration, the PPV of the mass point is the Y-direction vibration velocity. Therefore, for the 1-1 model, the $Y$-direction vibration velocity time comparison of the four measurement points is selected, and the $Y$-direction vibration velocity time curve of the 1-1 model \#1, \#2, \#3, and \#4 measurement points is plotted in Figure 7. It can be observed from Figure 8 that, for the No. 1-1 model of the excavation damping ditch, from the \#4 measuring point to the \#1 measuring point, the PPV is $9.274 \mathrm{~cm} / \mathrm{s}$ before the damping ditch wall, $2.718 \mathrm{~cm} / \mathrm{s}$ after the damping ditch wall, $2.134 \mathrm{~cm} / \mathrm{s}$ at the foot of the lighthouse, and $3.485 \mathrm{~cm} / \mathrm{s}$ at the 

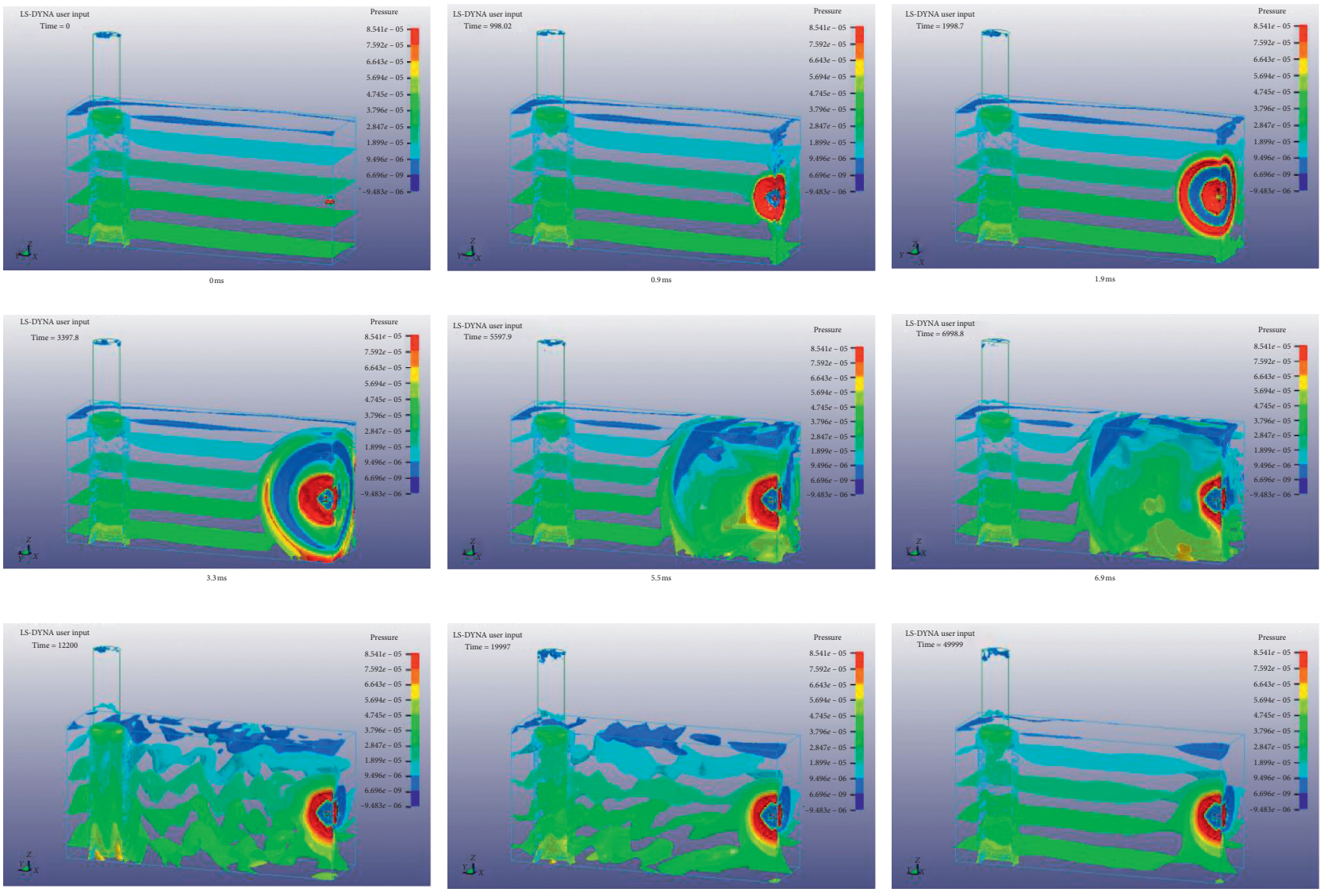

FIGURE 5: Vibration wave propagation.

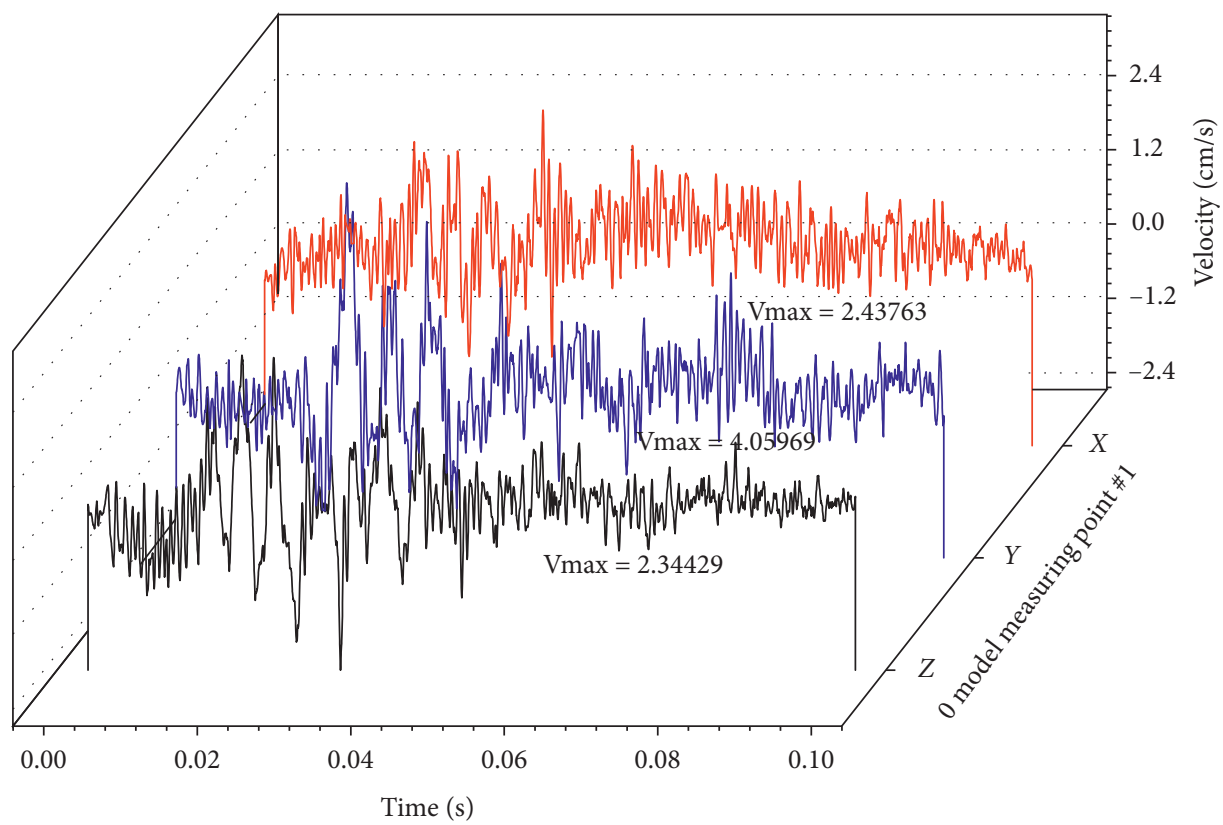

0 model-\#1 $X$-velocity
$-\quad 0$ model-\#1 $Y$-velocity
-0 model-\#1 $Z$-velocity

FIgURE 6: Vibration time history curves of the No. 0 model and \#1 measuring. 


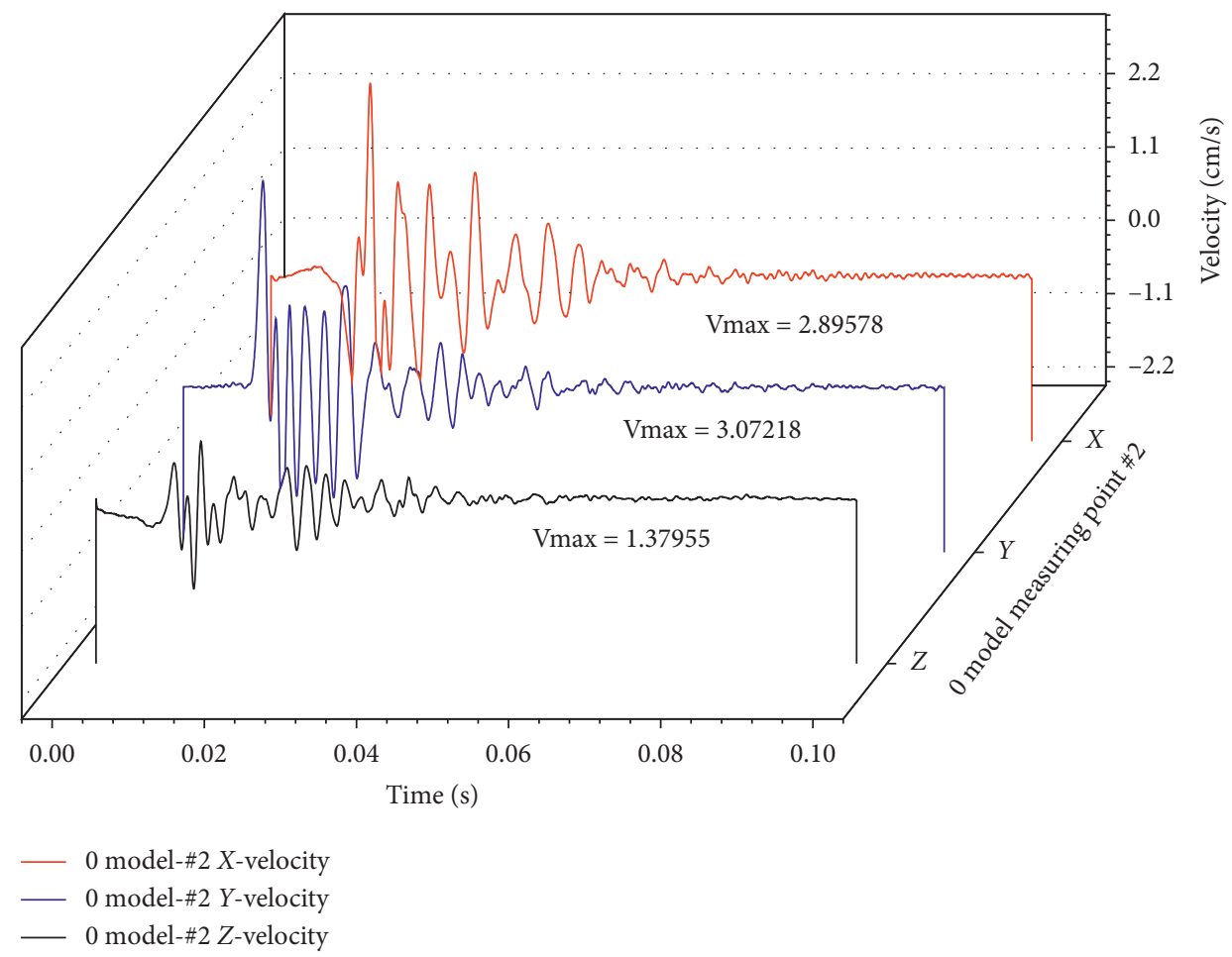

FIgURE 7: Vibration time history curves of the No. 0 model and \#2 measuring point.

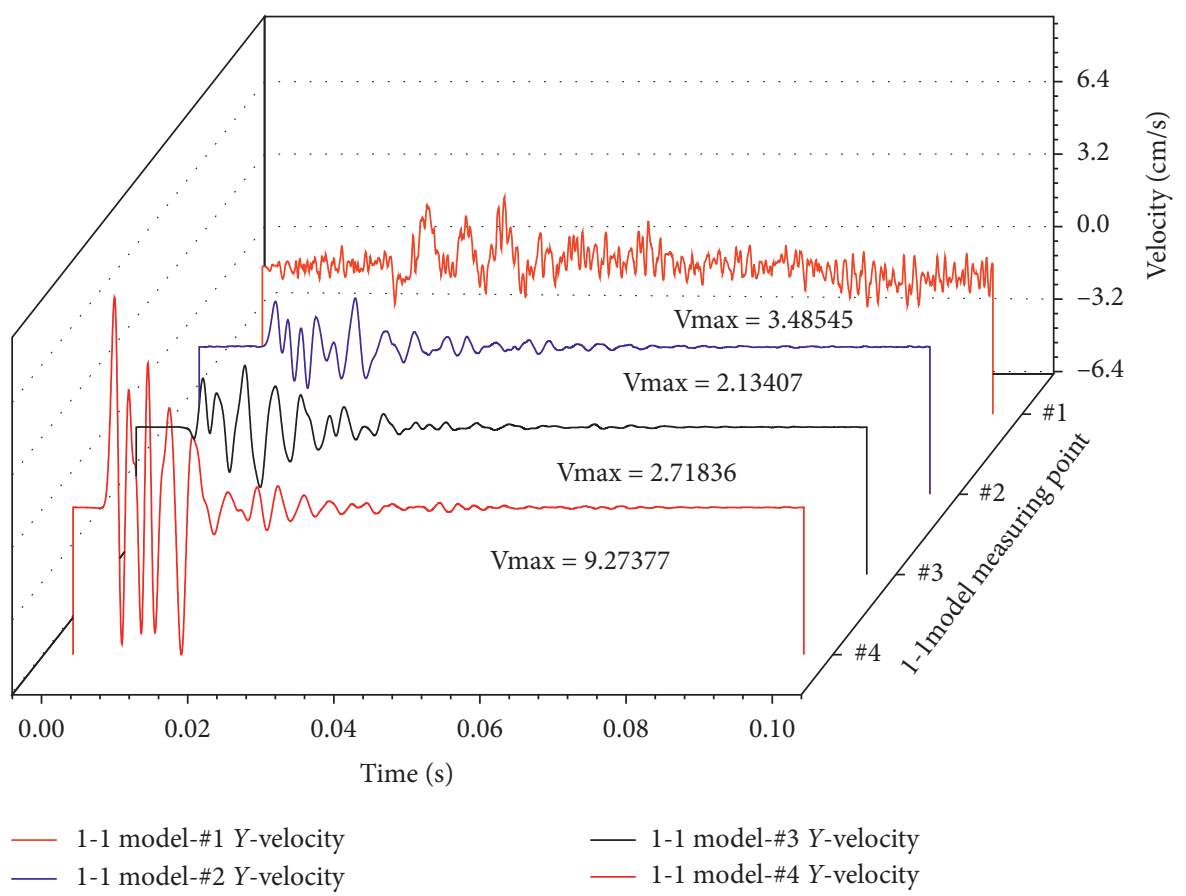

FIgURE 8: Vibration time history curves of the 1-1 Model for the \#1, \#2, \#3, and \#4 measuring points in the $Y$-direction.

top of the lighthouse. From the source of the explosion to the direction of the lighthouse, the PPV is reduced in turn, especially the PPV before and after the damping ditch is significantly smaller, and the PPV at the top of the tower is greater than the PPV at the foot of the lighthouse. All the models were calculated in turn, and the vibration data of the 
TABLE 6: PPV of numerical calculation in three directions.

\begin{tabular}{|c|c|c|c|c|c|c|c|c|c|c|c|c|}
\hline \multirow{2}{*}{$\begin{array}{l}\mathrm{PPV}(\mathrm{cm} / \mathrm{s}) \\
\text { Numbering }\end{array}$} & \multicolumn{3}{|c|}{ Measuring point $1 \#$} & \multicolumn{3}{|c|}{ Measuring point $2 \#$} & \multicolumn{3}{|c|}{ Measuring point $3 \#$} & \multicolumn{3}{|c|}{ Measuring point $4 \#$} \\
\hline & $X$ & $Y$ & $Z$ & $X$ & $Y$ & $Z$ & $X$ & $Y$ & $Z$ & $X$ & $Y$ & $Z$ \\
\hline 0 & 2.438 & 4.060 & 2.344 & 2.896 & 3.072 & 1.380 & & & & & & \\
\hline $1-1$ & 1.834 & 3.485 & 2.317 & 1.764 & 2.134 & 0.786 & 2.870 & 2.718 & 1.897 & 11.590 & 9.274 & 4.663 \\
\hline $1-2$ & 1.949 & 3.274 & 1.990 & 1.539 & 1.665 & 0.922 & 2.624 & 3.768 & 1.735 & 12.127 & 9.574 & 4.686 \\
\hline $1-3$ & 1.710 & 2.385 & 1.739 & 1.055 & 1.328 & 0.835 & 1.434 & 1.234 & 1.138 & 12.891 & 10.11 & 4.763 \\
\hline $1-4$ & 1.420 & 1.595 & 1.968 & 0.698 & 0.788 & 0.587 & 0.949 & 1.494 & 0.779 & 11.864 & 9.786 & 3.963 \\
\hline $2-1$ & 1.949 & 3.274 & 1.990 & 1.539 & 1.665 & 0.922 & 2.624 & 3.768 & 1.735 & 12.127 & 9.574 & 4.686 \\
\hline $2-2$ & 1.646 & 3.013 & 2.511 & 1.351 & 1.623 & 0.938 & 2.493 & 3.426 & 1.416 & 11.904 & 9.090 & 4.712 \\
\hline $2-3$ & 2.265 & 2.547 & 2.545 & 1.343 & 1.727 & 0.851 & 2.486 & 3.320 & 1.397 & 12.150 & 9.566 & 4.650 \\
\hline $2-4$ & 1.855 & 2.377 & 2.115 & 1.273 & 1.550 & 0.834 & 2.288 & 3.125 & 1.238 & 12.042 & 9.564 & 4.537 \\
\hline $3-1$ & 2.846 & 3.103 & 2.435 & 2.137 & 2.514 & 0.969 & 4.768 & 4.245 & 5.083 & 20.406 & 13.36 & 12.216 \\
\hline $3-2$ & 3.454 & 2.622 & 2.491 & 1.621 & 2.058 & 0.807 & 2.801 & 4.066 & 3.477 & 11.038 & 10.88 & 7.279 \\
\hline $3-3$ & 1.949 & 3.274 & 1.990 & 1.539 & 1.665 & 0.922 & 2.624 & 3.768 & 1.735 & 12.127 & 9.574 & 4.686 \\
\hline $3-4$ & 2.682 & 1.991 & 2.055 & 1.376 & 1.086 & 0.718 & 1.666 & 3.160 & 0.921 & 6.413 & 6.833 & 2.709 \\
\hline 4-1 & 3.514 & 3.348 & 2.133 & 2.414 & 2.746 & 1.030 & 4.613 & 4.539 & 4.927 & 17.813 & 12.10 & 11.744 \\
\hline 4-2 & 2.227 & 2.963 & 2.259 & 1.408 & 1.753 & 0.835 & 3.026 & 3.138 & 3.568 & 14.284 & 12.83 & 9.582 \\
\hline $4-3$ & 2.272 & 2.605 & 2.173 & 0.955 & 1.551 & 0.846 & 1.553 & 1.709 & 1.608 & 14.582 & 10.22 & 5.122 \\
\hline 4-4 & 2.299 & 2.292 & 2.306 & 0.971 & 0.934 & 0.670 & 1.333 & 1.611 & 0.846 & 13.254 & 10.46 & 4.269 \\
\hline
\end{tabular}

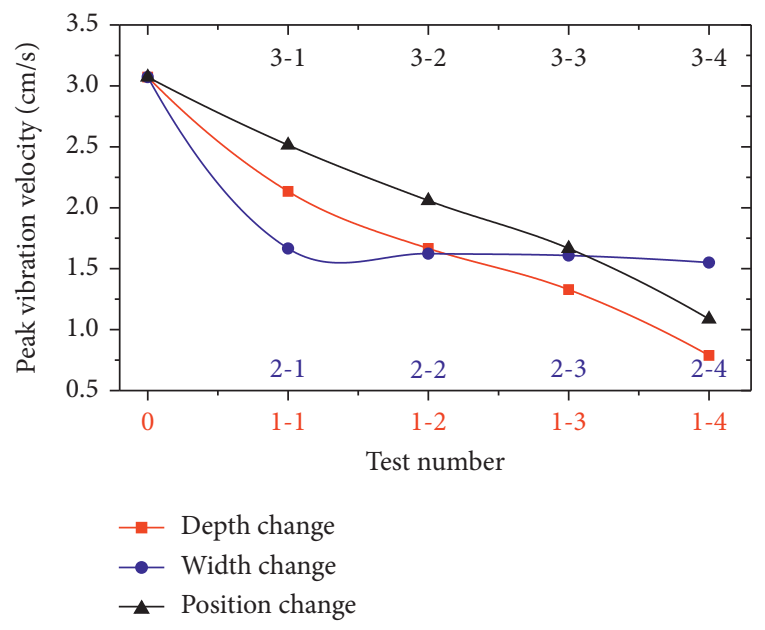

FIGURE 9: Influences of three damping ditch parameters on the PPV.

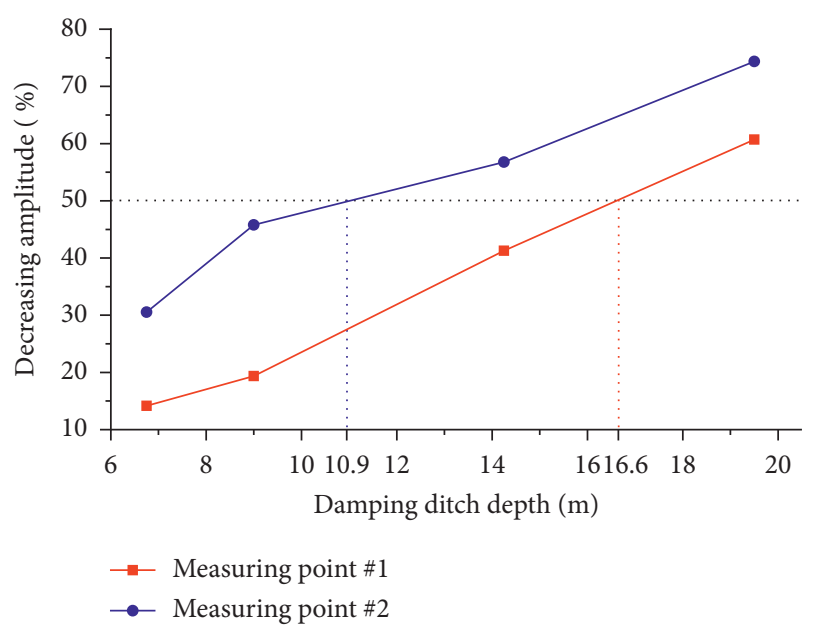

FIgURE 10: Damping ditch depth versus decreasing amplitude.

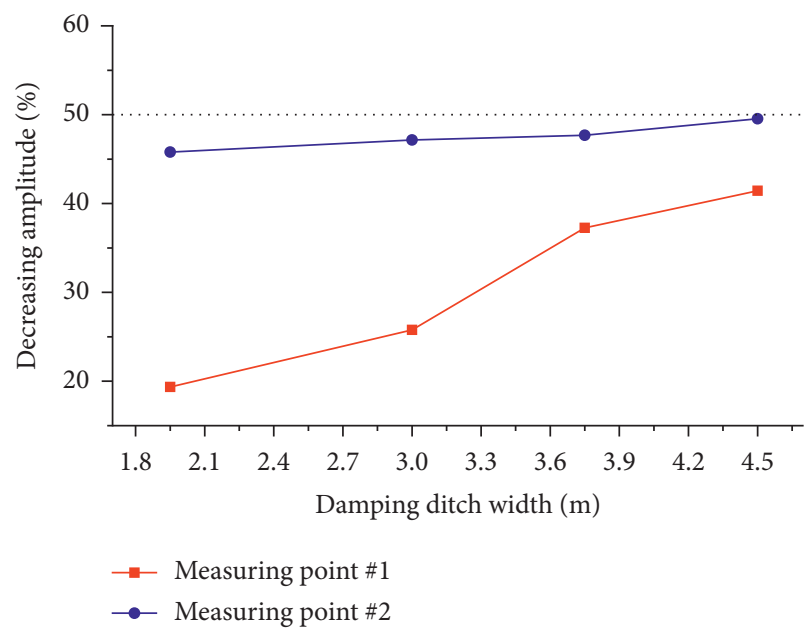

Figure 11: Damping ditch width versus decreasing amplitude.

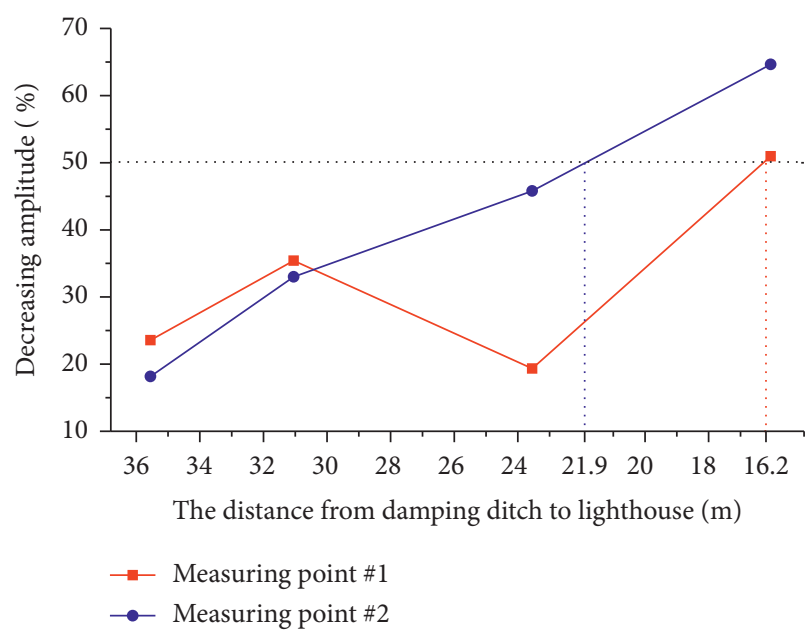

FIgURE 12: Damping ditch position versus decreasing amplitude. 
TABle 7: Calculated values of the Sadove transformation equation for the No. 0 model.

\begin{tabular}{|c|c|c|c|c|c|}
\hline Random measuring points & Velocity $(\mathrm{cm} / \mathrm{s})$ & $R(\mathrm{~m})$ & $Q(\mathrm{~kg})$ & $x$ & $y$ \\
\hline 1 & 5.663 & 45.717 & 600 & -1.690 & 1.734 \\
\hline 2 & 6.277 & 44.878 & 600 & -1.672 & 1.837 \\
\hline 3 & 7.055 & 45.144 & 600 & -1.678 & 1.954 \\
\hline 4 & 7.845 & 45.706 & 600 & -1.690 & 2.060 \\
\hline 5 & 7.296 & 39.205 & 600 & -1.536 & 1.987 \\
\hline 6 & 8.848 & 40.719 & 600 & -1.574 & 2.180 \\
\hline 7 & 9.130 & 36.592 & 600 & -1.468 & 2.212 \\
\hline 8 & 11.515 & 34.728 & 600 & -1.415 & 2.444 \\
\hline 9 & 12.325 & 34.074 & 600 & -1.396 & 2.512 \\
\hline 10 & 15.466 & 24.104 & 600 & -1.050 & 2.739 \\
\hline 11 & 9.518 & 40.025 & 600 & -1.557 & 2.253 \\
\hline 12 & 18.387 & 21.680 & 600 & -0.944 & 2.912 \\
\hline 13 & 13.344 & 31.639 & 600 & -1.322 & 2.591 \\
\hline 14 & 5.885 & 48.754 & 600 & -1.754 & 1.772 \\
\hline 15 & 16.363 & 22.495 & 600 & -0.981 & 2.795 \\
\hline
\end{tabular}

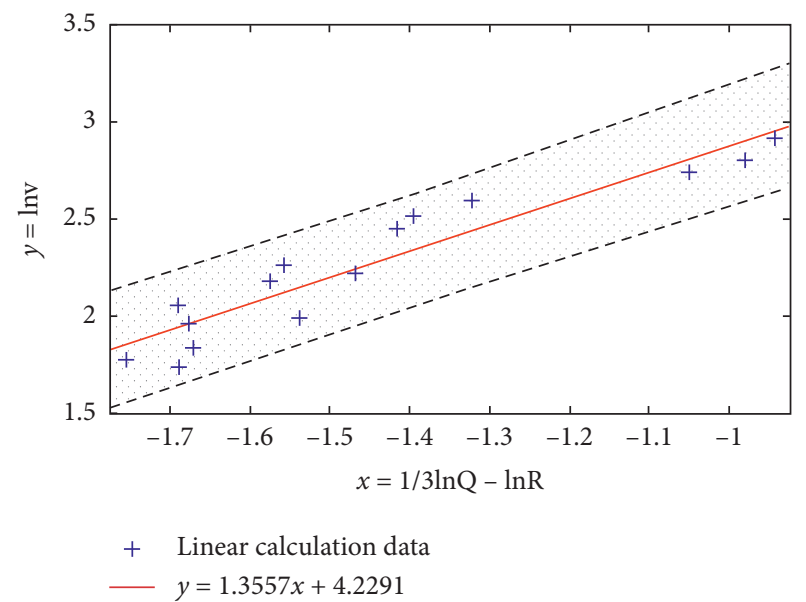

FIGURE 13: Fitted curve of the Sadove regression for the No. 0 model.

four measuring points in the $X, Y$, and $Z$ directions of each model were picked up, and the PPV is summarized in Table 6.

\section{Effect of Damping Ditch Parameters}

4.1. Effect of Depth, Width, and Position of the Damping Ditch. The PPV in the $Y$-direction of the \#1 and \#2 measuring points is determined to ascertain the effect of the different damping ditch parameters on the vibration. Figure 9 shows the PPV in the $Y$-direction for different damping ditch parameters in the three sets of tests.

It is observed in Figure 9 that, for the first group of experiments, the width and position of the damping ditch are unchanged; the depth of the damping ditch increases from 1-1 to 1-4, and the PPV of the \#2 measuring point decreases almost linearly. For the second set of tests, the depth and position of the damping ditch are unchanged and the width of the damping ditch increases from 2-1 to 2-4. At the beginning of \#2 measuring point, from the No. 0 model without a damping ditch to the $2-1$ model with the $1.3 \mathrm{~cm}$ damping ditch, the PPV decreases significantly. However, although the PPV decreases from 2-1 to 2-4, the change is very small and is almost horizontal. In the third group of tests, the depth and width of the damping ditch are constant and the position of the damping ditch changes from 3-1 to 34 and the horizontal distance from the lighthouse decreases. It can be seen that the PPV is significantly reduced and the trend is similar to that of the deepening vibration decreasing trend, but the decreasing amplitude is smaller when the depth increased.

In summary, the width of the damping ditch has no apparent effect on the vibration attenuation in the remote area of the blasting. The depth and the position of the damping ditch are the main factors influencing the damping effect of the ditch. In an actual project, the depth and position of the damping ditch should be the major concern, whereas the width is a secondary factor.

4.2. Effect of Damping Ditch Parameters on the Vibration Attenuation. The above qualitative analysis of the impact of different sizes and positions of the damping ditch on the damping effect, and then a quantitative analysis of the impact of different ditch sizes and positions on the damping effect in each group of tests. We compared the PPV in the $Y$ direction of each model for the \#1 and \#2 measurement points of the first group of tests with that of the No. 0 model. We then calculated the degree of attenuation for different damping ditch depths, as shown in Figure 10.

It can be seen in Figure 10 that the vibration attenuation increases as the depth of the damping ditch increases. The intersections of the lines of the $\# 1$ and the $\# 2$ measuring points and the $50 \%$ line of the attenuation amplitude show the damping ditch depth for a damping ditch width of $1.95 \mathrm{~m}$ and a horizontal distance from the lighthouse of $23.5 \mathrm{~m}$. When the depth of the damping ditch exceeds $10.9 \mathrm{~m}$, the amplitude of the \#2 measuring point on the ground is larger than $50 \%$. For the \#1 measuring point at the top of the tower, the attenuation of the amplitude reduction is larger than $50 \%$ when the depth of the damping ditch exceeds $16.6 \mathrm{~m}$. This shows that, with the increase in the depth of the damping ditch, the amplitude reduction can be 


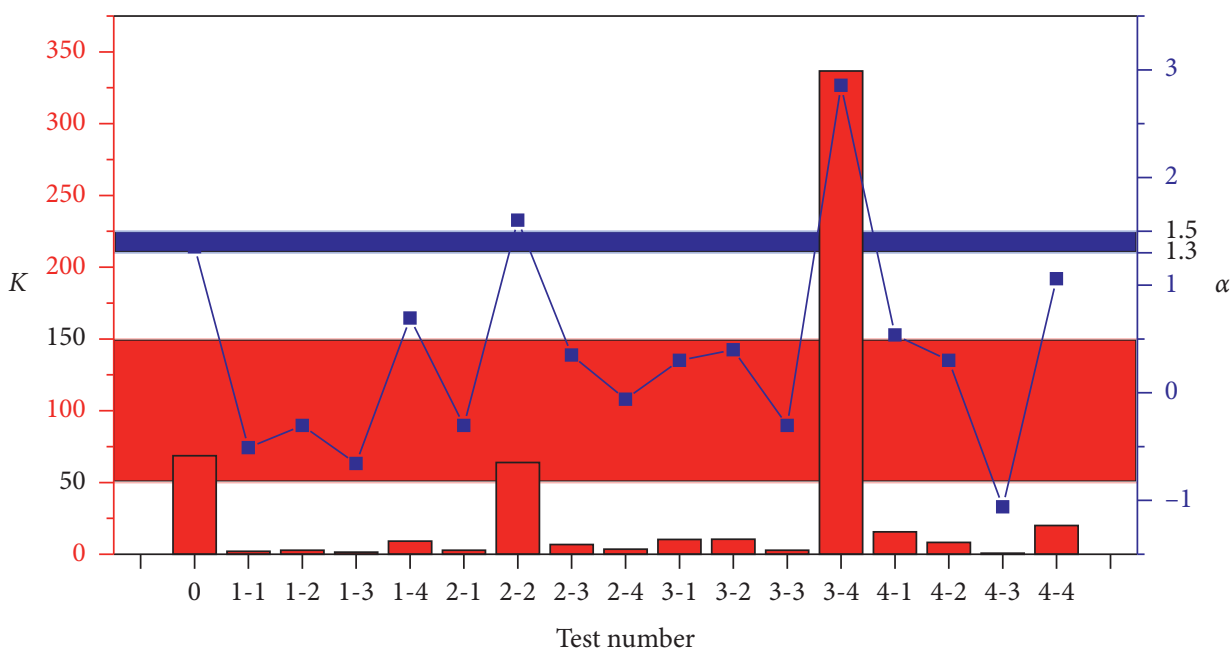

FIGURE 14: Sadove regression parameters for each model.

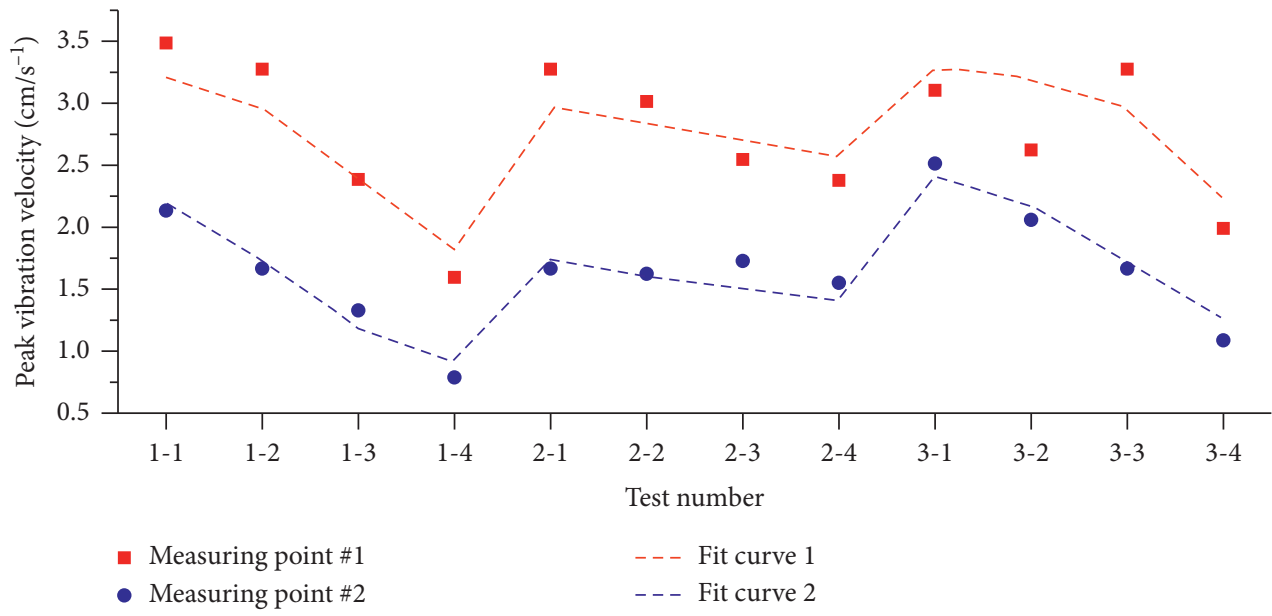

FIgURE 15: Regression fitting for the PPV and three factors.

TABLE 8: Comparison of calculated values and measured values of the fourth set of measuring points.

\begin{tabular}{|c|c|c|c|c|c|c|c|}
\hline \multicolumn{2}{|c|}{ Fourth group } & \multicolumn{3}{|c|}{ Measuring point \#1 } & \multicolumn{3}{|c|}{ Measuring point \#2 } \\
\hline$d$ & $s$ & Test velocity & Calculated velocity & Difference & Test velocity & Calculated velocity & Difference \\
\hline 7.5 & 31.35 & 3.348 & 3.411 & -0.062 & 2.746 & 2.668 & 0.078 \\
\hline 11.25 & 31.35 & 2.963 & 2.998 & -0.035 & 1.753 & 1.906 & -0.153 \\
\hline 12.75 & 24.15 & 2.605 & 2.658 & -0.053 & 1.551 & 1.412 & 0.139 \\
\hline 17.25 & 19.35 & 2.292 & 1.923 & 0.369 & 0.934 & 0.930 & 0.004 \\
\hline
\end{tabular}

increased at the ground and the top of buildings and that the vibration damping effect is better at the ground than at the top of tall buildings.

We then compared the PPV in the $Y$-direction of each model for the \#1 and \#2 points of the second group of tests with that of the No. 0 model and calculated the degree of attenuation for different damping ditch widths; the results are shown in Figure 11.
It is observed in Figure 11 that as the width of the damping ditch increases, the attenuation amplitude of the \#1 measuring point increases and that of the \#2 measuring point is basically unchanged. This indicates that the change in the width of the damping ditch does not affect the PPV measured at the surface but does affect the damping performance at the top of the tower. Therefore, an increase in the damping ditch width increases the amplitude reduction 
in tall buildings. However, in this test, the amplitude reduction remains below 50\%, even when the damping ditch width is $4.5 \mathrm{~m}$. At the ground, the changes in the amplitude reduction with increasing width of the damping ditch are almost negligible.

We then compared the PPV in the $Y$-direction of each model for the \#1 and \#2 points of the third group of tests with that of the No. 0 model and calculated the degree of attenuation for different damping ditch positions; the results are shown in Figure 12.

It can be seen in Figure 12 that the attenuation amplitude of the \#1 and \#2 measuring points increases as the horizontal distance of the damping ditch from the lighthouse decreases. Therefore, the smaller the distance from the building, the better the damping effect. The intersections of the lines of the $\# 1$ and \#2 measuring points and the 50\% line of the attenuation amplitude show that the horizontal distance of the damping ditch from the lighthouse is less than $21.9 \mathrm{~m}$ for a damping ditch depth of $9 \mathrm{~m}$ and a width of $1.95 \mathrm{~m}$. For the \#2 measuring point at the surface, the amplitude reduction is more than $50 \%$. For the \#1 measuring point at the top of the tower, the damping amplitude is $50 \%$ or larger when the horizontal distance of the damping ditch from the lighthouse is less than $16.2 \mathrm{~m}$. This shows that as the distance between the damping ditch and the building is reduced, the amplitude reduction significantly increases at the ground and the top of buildings and the damping effect is better at the top of the building than at the ground level.

\section{Derivation of Vibration Attenuation Formula for Different Damping Ditch Sizes and Positions}

The vibration damping effect of damping ditches with different parameters was discussed above. Next, we use the vibration data to predict the blasting vibration for different damping ditch sizes and positions. It was demonstrated in the above discussion that the numerical model was reliable. The accurate prediction of the blasting vibration attenuation is the basis for blasting design and safety. The purpose of the blasting vibration calculation is to predict the safe vibration speed for the target building. Therefore, we conducted a vibration velocity regression analysis using the vibration data for different damping ditch parameters obtained from the numerical simulations. The objective was to derive an equation for the blasting vibration strength for different damping ditches.

5.1. Regression Analysis of the Sadove Equation in the Presence of the Damping Ditch. The vibration velocity of mass points is often used as the standard for evaluating the blasting vibration intensity in practical engineering applications but it is difficult to derive the specific mathematical function expression to calculate the blasting vibration intensity. Generally, the blasting vibration intensity is predicted using a binary linear regression analysis of the measured particle vibration velocity. Many empirical formulas for predicting the blasting vibration intensity have been developed in
China and abroad. The approach most commonly used in China is the empirical formula of the spur vibration intensity proposed by Peng et al. [31]:

$$
V=K\left(\frac{\sqrt[3]{\mathrm{Q}}}{R}\right)^{\alpha}
$$

where $V$ is the blasting vibration speed; $K$ and $\alpha$ are the coefficients related to the blasting conditions and geological conditions; $Q$ is the charge weight; and $R$ is the blast center distance. In order to determine the undetermined coefficients $K$ and $\alpha$ in equation (4), it is necessary to convert equation (4) into a linear function and use the logarithm on both sides:

$$
\ln v=\ln k+\alpha\left(\frac{1}{3} \ln Q-\ln R\right)
$$

We use $y=\ln v, \quad x=1 / 3 \ln Q-\ln R, \quad a=\alpha$, and $b=\ln k$. Then, equation (5) is transformed into

$$
y=a x+b .
$$

We randomly select 15 vibration measuring points from the numerical simulation model No. 0 . The vibration velocity $v$, the blasting distance $R$, and the blasting dose $Q$ of each point are obtained, and equations (4)-(6) are calculated; the results are shown in Table 7.

The MATLAB multiple linear regression function $b$, bint, $r$, rint, ststs $]=$ regress $(y, x$, alpha $)$ was used to calculate the data in Table 6 [32], where $b$ is the regression coefficient estimate; brint is the confidence interval of $b$; $r$ is the column difference column vector; rint is the residual and its confidence interval; stats is the statistic used to test the regression model; $x, y$ are independent and dependent variables; and alpha is the level of significance (default is 0.5 ). The vibration velocity regression results and the fitted curve are shown in Figure 13.

As shown in Figure 13, the vibration regression model of model 0 is

$$
y=1.355 x+4.229
$$

The correlation coefficient of the fitted curve is 0.9528 , indicating a good fit of the regression model. Using equation (7), the regression coefficient of the Sadove formula can be calculated, providing $k=68.656$ and $\alpha=1.355$. Thus, the equation for calculating the vibration velocity of model 0 is obtained:

$$
V=68.657\left(\frac{\sqrt[3]{Q}}{R}\right)^{1.3557}
$$

Using this method, 15 measuring points were selected for each numerical model of the experiment and the regression coefficients of the Sadove equation were calculated. The results are shown in Figure 14.

According to the "Blasting Safety Regulations" (GB67222011) [33], the hardness of the hard rock is $K=50-150$ and $\alpha=1.3-1.5$. It can be seen in Figure 14 that only the No. 0 
model without the damping ditch $(K=68.6566, \alpha=1.3557)$ meets the empirical values of the blasting safety regulations. Therefore, when there is no damping ditch, the attenuation behavior of the ground blasting vibration is in agreement with the Sadove equation and the blasting vibration can be predicted using the Sadove equation. Except for model No. 0 , only the $K$ value of the 2-2 model is in the range of blasting vibration values in the standard. For the rest of the models with the damping ditch, the differences in the regression coefficients of the blasting vibration attenuation are large and are not within the scope of the regulations. Only the correlation coefficient of model No. 0 is sufficiently high at 0.9528 , whereas the other correlation coefficients are below 0.9 . This indicates that when a damping ditch is present, the vibration prediction of the Sadove equation does not meet the engineering requirements and it is necessary to reevaluate the vibration attenuation equation in the presence of the damping ditch.

5.2. Fitting Equation of the PPV for Different Sizes and Positions of the Damping Ditch. This experiment considers the influence of the size and position of the damping ditch on the vibration attenuation. Therefore, the size and position of the damping ditch are used as independent variables and the PPV at the top and bottom of the lighthouse are used as the dependent variables to fit the PPV attenuation equation for different damping ditch parameters. The depth and width of the damping ditch and the horizontal distance from the lighthouse are used as independent variables. In this case, there are many independent variables. Our analysis demonstrated that the damping ditch width had less of an influence on the PPV at the ground and the top of the tower than the depth and position of the damping ditch. In order to easily and accurately fit the equation of the vibration attenuation, we added the width of the damping ditch to the horizontal distance between the ditch and the lighthouse. This means that the two factors of the width of the damping ditch and the horizontal distance between the ditch and the lighthouse are combined into one parameter, which is renamed as the horizontal distance of the damping ditch to the lighthouse. The three influencing factors are simplified into two factors: the depth of the damping ditch and the horizontal distance of the damping ditch to the lighthouse.

The PPV in the Y-direction of the first three sets of experiments at the $\# 1$ and the $\# 2$ measuring points correspond to the damping ditch depth and the horizontal distance to the lighthouse. We used the 1stOpt software for formula fitting. In order to facilitate the expression of the formula, the PPV, the depth of the damping ditch, and the horizontal distance of the damping ditch to the lighthouse are expressed as $V, d$, and $s$, respectively. Using the 1stOpt fast fitting function, the PPV in the $Y$-direction of the \#1 and the \#2 measuring point is fitted to the horizontal distance of the damping ditch depth and the damping ditch distance from the lighthouse. For convenience, only the best fitting formula of the three parameters is selected. The fitted curve is shown in Figure 15.
The PPV attenuation equation of the \# 1 measuring point of the lighthouse is

$$
v=4.491-0.11 d-\frac{251.064}{s^{2}} .
$$

The correlation coefficient of equation (9) is 0.868.v

The PPV attenuation equation of the \#2 measuring point of the lighthouse is

$$
v=1.062 d^{-0.829} \cdot s^{0.752} .
$$

The correlation coefficient of equation (10) is 0.973 .

The PPV in the $Y$-direction of the \#1 and \#2 measuring points of the fourth group of the test was verified. The corresponding values of the width, position, and depth of the damping ditch in each model of the fourth group are used in equations (8) and (9). The vibration values are obtained and are listed together with the measured values of the previous test in Table 8.

The results in Table 8 show that, for the \# 1 measuring point at the top of the lighthouse, the difference between the first three calculated values and the measured value is less than $0.1 \mathrm{~cm} / \mathrm{s}$ but the difference for the fourth value is $0.37 \mathrm{~cm} / \mathrm{s}$. This occurred because the \#1 measuring point is at the top of the tower and is affected by the height; it is impossible to obtain an accurate value of the vibration velocity of each measuring point. The fitting accuracy is not very high; therefore, there is a big difference between the fourth calculated value and the test value. However, the first three calculations meet the engineering needs. For the \#2 measuring point at the base of the lighthouse, the difference between the calculated value and the measured value is less than $0.2 \mathrm{~cm} / \mathrm{s}$ and the accuracy meets the engineering needs. The regression formula of the vibration damping velocity obtained from this test is appropriate for this experiment. For buildings that have safe vibration velocity limits and when the excavation of the damping ditches is limited due to site conditions, as long as either $d$ or $\mathrm{s}$ is determined, the values for the other parameters of the damping ditch can be estimated by using the equation for the vibration velocity. This achieves the optimum damping effect for the most economical excavation size.

\section{Conclusion}

In this study, against the background of the Lufeng Nuclear Power Plant Phase II A3 regional field blasting project, we conducted numerical simulations and indoor model tests to determine the damping effect of damping ditches with different depths, widths, and positions and the PPV at the base and the top of a lighthouse.

The following conclusions can be drawn:

(1) The damping ditch width does not affect the velocity vibrations at the base of the lighthouse at the $\# 2$ measuring point but there is a damping effect at the \#1 measuring point at the top of the lighthouse. This shows that an increase in the width of the damping ditch has nearly negligible effects on the amplitude reduction at the base of buildings but has significant 
effects on the amplitude reduction at the top of tall buildings.

(2) The depth and position of the damping ditch are the main factors affecting the damping effect. As the depth of the damping ditch increases or the distance to the building decreases, the vibration speed decreases significantly at the \#1 and \#2 measuring points. Moreover, the increase in the depth of the damping ditch improves the damping effect at the base of the building to a greater degree than at the top of the tall building. However, when the distance between the damping ditch and the building is reduced, the damping effect is greater at the top of the building.

(3) In the presence of a damping ditch, the Sadove vibration prediction equation does not meet the requirements of practical applications. The vibration attenuation equations were fitted for different sizes and positions of the damping ditch and at the top and the base of the lighthouse. A comparison with the fourth set of verification tests indicated that the calculated values were in agreement with the measured values. The results of this study provide guidance for engineering excavations and layout of damping ditches.

\section{Data Availability}

The data used to support the findings of this study are available from the corresponding author upon request.

\section{Conflicts of Interest}

The authors declare that they have no conflicts of interest.

\section{Acknowledgments}

This paper was supported by the National Natural Science Foundation of China (No. 50778017).

\section{References}

[1] J. Wang, Y. Lu, and Z. F. Fang, "Numerical analysis of influence of groove on propagation vibration attenuation," Highway, China Communications Construction Group Corporation Limited.vol. 62, pp. 48-52, 2017, in Chinese.

[2] D. Y. Yu, J. Yang, and M. S. Zhao, "Study on the absorption mechanism of damping bitch to the vibration wave in bench blasting," Journal of china Coal Society, vol. 36, no. 2, pp. 244-247, 2011, in Chinese.

[3] P. Zoccali, G. Cantisani, and G. Loprencipe, "Ground-vibrations induced by trains: filled trenches mitigation capacity and length influence," Construction and Building Materials, vol. 74, pp. 1-8, 2015.

[4] P. Persson, K. Persson, and G. Sandberg, "Numerical study of reduction in ground vibrations by using barriers," Engineering Structures, vol. 115, pp. 18-27, 2016.

[5] A. Saikia and U. K. Das, "Analysis and design of open trench barriers in screening steady-state surface vibrations," Earthquake Engineering and Engineering Vibration, vol. 13, no. 3, pp. 545-554, 2014.
[6] A. Saikia, "Numerical study on screening of surface waves using a pair of softer backfilled trenches," Soil Dynamics and Earthquake Engineering, vol. 65, pp. 206-213, 2014.

[7] M. Esmaeili, J. A. Zakeri, and S. A. Mosayebi, "Investigating the optimized open $\mathrm{V}$-shaped trench performance in reduction of train-induced ground vibrations," International Journal of Geomechanics, vol. 14, no. 3, 2014.

[8] J.-A. Zakeri, M. Esmaeili, and S.-A. Mosayebi, "Numerical investigation of the effectiveness of a step-shaped trench in reducing train-induced vibrations," Proceedings of the Institution of Mechanical Engineers, Part F: Journal of Rail and Rapid Transit, vol. 228, no. 3, pp. 298-306, 2014.

[9] M. Jesmani, A. M. Fallahi, and H. F. Kashani, "Effects of geometrical properties of rectangular trenches intended for passive isolation in sandy soils," Earth Science Research, vol. 1, no. 2, pp. 137-151, 2012.

[10] D. J. Thompson, J. Jiang, M. G. R. Toward et al., "Reducing railway-induced ground-borne vibration by using open trenches and soft-filled barriers," Soil Dynamics and Earthquake Engineering, vol. 88, pp. 45-59, 2016.

[11] N. Hamdan, O. Laghrouche, P. K. Woodward, and M. S. Mahmood, "Ground vibration reduction analysis using a frequency-domain finite element approach," Construction \& Building Materials, vol. 92, pp. 95-103, 2014.

[12] C. Van hoorickx, M. Schevenels, and G. Lombaert, "Double wall barriers for the reduction of ground vibration transmission," Soil Dynamics and Earthquake Engineering, vol. 97, pp. 1-13, 2017.

[13] D. Younesian and M. Sadri, "Performance analysis of multiple trenches in train-induced wave mitigation," Journal of Low Frequency Noise, Vibration and Active Control, vol. 33, no. 1, pp. 47-63, 2014.

[14] S. H. Ju and H. C. Li, "3D analyses of open trench barriers filled with water," Journal of Geotechnical and Geoenvironmental Engineering, vol. 137, no. 11, pp. 1114-1120, 2011.

[15] J. Barbosa, P. Alves Costa, and R. Calçada, "Abatement of railway induced vibrations: numerical comparison of trench solutions," Engineering Analysis with Boundary Elements, vol. 55, pp. 122-139, 2015.

[16] K. Ding, X. Fang, L. Fan, D. Li, and Y. Y. Zhang, "Characteristics variation of blasting seismic wave energy affected by a damping ditch," Journal of Vibration and Shock, vol. 31, no. 13, pp. 113-118, 2012, in Chinese.

[17] S. M. Zheng, Y. S. Yao, and X. C. Zeng, "Vibration-isolating effect of vibration-isolating slot in project site," Blasting, vol. 25, no. 3, pp. 103-106, 2008, in Chinese.

[18] D. Ulgen and O. Toygar, "Screening effectiveness of open and in-filled wave barriers: a full-scale experimental study," Construction and Building Materials, vol. 86, pp. 12-20, 2015.

[19] S. D. Ekanayake, D. S. Liyanapathirana, and C. J. Leo, "Attenuation of ground vibrations using in-filled wave barriers," Soil Dynamics and Earthquake Engineering, vol. 67, pp. 290-300, 2014.

[20] A. Alzawi and M. Hesham El Naggar, "Full scale experimental study on vibration scattering using open and in-filled (GeoFoam) wave barriers," Soil Dynamics and Earthquake Engineering, vol. 31, no. 3, pp. 306-317, 2011.

[21] P. Jayawardana, R. Achuhan, G. H. M. J. S. De Silva, and D. P. Thambiratnam, "Use of in-filled trenches to screen ground vibration due to impact pile driving: experimental and numerical study," Heliyon, vol. 4, no. 8, Article ID e00726, 2018. 
[22] N. Babanouri, H. Mansouri, S. K. Nasab, and M. Bahaadini, "A coupled method to study blast wave propagation in fractured rock masses and estimate unknown properties," Computers and Geotechnics, vol. 49, no. 4, pp. 134-142, 2013.

[23] F. G. Zhang and E. Z. Li, "A method to determine the parameters of the model for concrete impact and damage," Journal of Ballistics, vol. 4, p. 51, 2001.

[24] Livermore Software Technology Corporation, ANSYS/LSDYNA Theoretical Manual, Livermore Software Technology Corporation, Livemore, CA, USA, 1998.

[25] Y. S. Tai, T. L. Chu, H. T. Hu, and J. Y. Wu, "Dynamic response of a reinforced concrete slab subjected to air blast load," Theoretical and Applied Fracture Mechanics, vol. 56, no. 3, pp. 140-147, 2011.

[26] Z.-1. Wang, J. G. Wang, Y.-C. Li, and C. F. Leung, "Attenuation effect of artificial cavity on air-blast waves in an intelligent defense layer," Computers and Geotechnics, vol. 33, no. 2, pp. 132-141, 2006.

[27] R. Castedo, P. Segarra, A. Alañon, L. M. Lopez, A. P. Santos, and J. A. Sanchidrián, "Air blast resistance of full-scale slabs with different compositions: numerical modeling and field validation," International Journal of Impact Engineering, vol. 86, pp. 145-156, 2015.

[28] W. Li, X. Wang, and W. Li, “The effect of annular multi-point initiation on the formation and penetration of an explosively formed penetrator," International Journal of Impact Engineering, vol. 37, no. 4, pp. 414-424, 2009.

[29] X. M. Zhang, D. Cui, H. J. Jia, and H. Liang, "Numerical simulation study on damage mechanism of throat armor," Advanced Materials Research, vol. 149, pp. 289-292, 2011.

[30] K.-C. Wu, B. Li, and K.-C. Tsai, "Residual axial compression capacity of localized blast-damaged RC columns," International Journal of Impact Engineering, vol. 38, no. 1, pp. 29-40, 2011.

[31] Y. Peng, L. Wu, C. Chen, B. Zhu, and Q. Jia, "Study on the robust regression of the prediction of vibration velocity in underwater drilling and blasting," Arabian Journal for Science and Engineering, vol. 43, pp. 55411-55549, 2018.

[32] E. Ghasemi, M. Ataei, and H. Hashemolhosseini, "Development of a fuzzy model for predicting ground vibration caused by rock blasting in surface mining," Journal of Vibration and Control, vol. 19, no. 5, pp. 755-770, 2013.

[33] China Society of Engineering Blasting, Safety Regulations for Blasting (GB 6722-2011), Standards Press of China, Beijing, China, 2011. 